\title{
Nodules of Scalp in Infant: What is your Diagnosis
}

\author{
Chaoui R*, El Kadiri S, Oukarfi S, Douhi Z, Baybay H, Elloudi S and Mernissi \\ FZ \\ Department of Dermatology, University Hospital Hassan II, Morocco \\ Letter to Editor \\ Volume 5 Issue 1 \\ Received Date: January 10, 2020 \\ Published Date: January 24, 2020 \\ DOI: $10.23880 /$ cdoaj-16000201 \\ Hassan II, Fez, Morocco, Tel: 212675222761; Email: chaoui.rhizlane@gmail.com
}

Keywords: Juvenile xanthogranuloma; Chilhood; Dermoscopy

Sir,

A 6 week-old boy, was evaluated for 2 asymptomatic,erythematous lesions on the right scalp vertex that was present 7 days after birth. He was otherwise healthy.

Dermatological examination revealed two wellcircumscribed papule and nodule , erythematous in color,7$10 \mathrm{~mm}$ in diameter with firm consistency, located on the right scalp vertex (Figure 1). The rest of the physical examination was normal. An ophthalmologic examination was performed and was normal.

On dermoscopy, we observed a yellow center with erythematous halo, characterizing the "setting sun" pattern (Figure 2). These findings, in correlation with clinical examination, supported the diagnosis of JXG.

A conservative treatment was adopted.

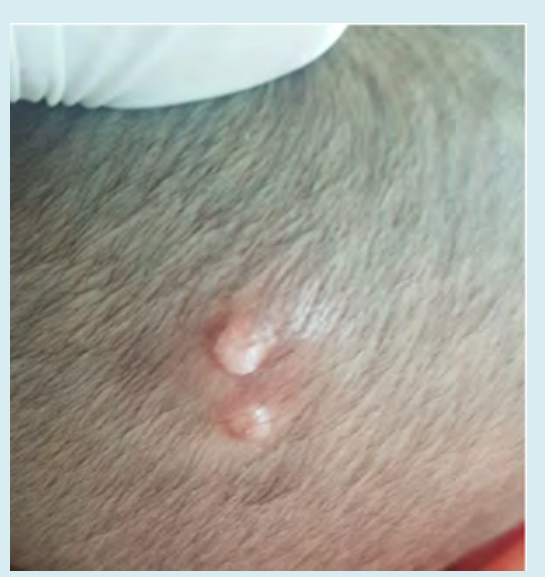

Figure 1: Two well-circumscribed papule and nodule, erythematous in color, $7-10 \mathrm{~mm}$ in diameter, located on the right scalp vertex.

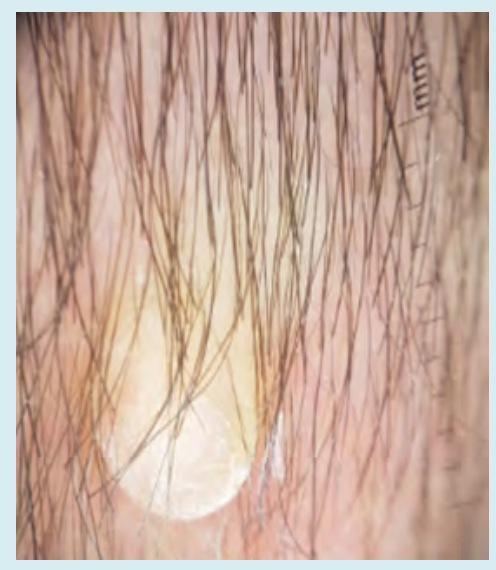

Figure 2: Yellow center with erythematous halo.

Juvenile xanthogranuloma(JXG) was first described by H.G. Adamson in 1905 and named by Helwig and Hackney in 1954 [1]. It is the most common form of non-Langerhans cell histiocytosis [2]. It may be present at birth, in infancy, early childhood and also in adults of all ages.Its etiology still unknown but has been hypothesized to result from a disordered histiocytic response to non-specific injury [3].

Clinically, JXG is characterized by solitary or multiple,reddish or yellowish, papules or nodules with firm consistency which usually resolve spontaneously. The most commonly reported location for JXG was the head and neck, followed by the trunk, lower extremities, and then upper extremities [4].

Extra-cutaneous involvement, of JXG, may occur in about $5 \%$ of children. Ocular involvement particularly the uveal tract is the most frequent extracutaneous location and can occur without concomitant skin involvement [5]. 
Clinical Dermatology Open Access Journal

Other extracutaneous locations of JXG have been described lung, heart, kidney,central nervous system, adrenal gland, gastrointestinal system, pituitary gland, bones and bone marrow.

The diagnosis of JXG is mainly based on characteristic clinical features. However, dermoscopy is a non invasive and a helpful tool that has been used to support diagnosis of JXG.

Various dermoscopic features of juvenile xanthogranuloma have been reported including discrete pigment network, whitish streaks,linear telangiectasias and fine, branched vessels [6], but the characteristic dermoscopic feature that has been described is "sun dermoscopic pattern » defined by a yellow-orange background surrounded by erythematous border [7].

In some atypical cases,It was necessary to practice a skin biopsy for confirmation of diagnosis. Characteristic histologic findings in JXG are: dense dermal histiocytic infiltrate and Touton Giant cells which are multinucleated, with homogeneous eosinophilic cytoplasmic center and xanthomatization in the periphery [2].

Immunohistochemical stains are typically positive for factor XIIIa, CD68, CD163, fascin, and CD14. Stains are typically negative for S-100 protein and CD1a, markers for Langerhans cells.

Considering the benign nature of the disease and its tendency to spontaneous resolution,conservative treatment may be adopted. In some doubtful cases a skin biopsy or outright surgical excision is recommended to confirm the diagnosis.

\section{Conflict of Interest}

The authors do not declare any conflict of interest.

\section{Contributions of Authors}

All authors contributed to the writing of this article. The authors also state that they have read and approved the final version.

\section{References}

1. Helwig EB, Hackney VC (1954) Juvenile xanthogranuloma (nevoxanthoendothelioma). Am J Pathol 30: 625-626.

2. Pajaziti L, Hapçiu S, Pajaziti A (2014) Juvenile xanthogranuloma: a case report and review of the literature. BMC Res Notes 7(1): 174.

3. Herbst AM, Laude TA (1999) Juvenile xanthogranuloma: further evidence of a reactive etiology. Pediatr Dermatol 16(2): 164 .

4. Dehner LP (2003) Juvenile xanthogranulomas in the first two decades of life: a clinicopathologic study of 174 cases with cutaneous and extracutaneous manifestations. Am J Surg Pathol 27(5): 579-593.

5. Liang S, Liu YH, Fang K (2009) Juvenile xanthogranuloma with ocular involvement. Pediatr Dermatol 26(2): 232234.

6. Oliveira TE de, Tarlé RG, Mesquita LA de F (2018) Dermoscopy in the diagnosis of juvenile xanthogranuloma. Anais Brasileiros de Dermatologia 93(1): 138-140.

7. Litaiem N,ZeglaouiF(2018) Is thesettingsun dermoscopic pattern specific to juvenile xanthogranuloma? J Am Acad Dermatol 78(2): 49. 